\title{
A Clinical Scenario of Corneal Ulcer in A Rural Based Hospital
}

\author{
Author \\ Dr M.R.Madhavi ${ }^{1}$, Dr K.Vijaykumar ${ }^{2}$, Dr Prachee Nagrale ${ }^{3}$, Dr Tejaswi Gude ${ }^{4}$ \\ ${ }^{1}$ Associate Professor, Department of Ophthalmology,Mamata Medical college, Khammam. \\ ${ }^{2}$ Professor \& HOD, Department of Ophthalmology, Mamata Medical College, Khammam \\ ${ }^{3}$ Assistant Professor, Department of Ophthalmology, Mamata Medical College, Khammam \\ ${ }^{4}$ Senior Resident, Department of Ophthalmology, Mamata Medical College, Khammam
}

\begin{abstract}
Purpose: Corneal ulcer is one of the major causes of blindness in developing countries Predisposing factors related to corneal ulcer are trauma, chronic ocular surface disease, contact lens usage, ocular surgery, corneal anaesthetic abuse, Diabetes mellitus, Vitamin deficiency, immunodeficiencies. Bacteria and fungi are frequently responsible for suppurative corneal ulcers. This study attempts in finding the etiology of corneal ulcers and its profile of clinical presentation and response to treatment in patients attending to a rural based hospital.

Setting: Study was conducted and the data was collected at Mamata General Hospital, Khammam

Design: The study design is a prospective cross-sectional study without any masking.

Methods: The present study of aetiology and treatment of corneal ulcer was undertaken on the patients attending to Ophthalmic department of Mamata General Hospital, Khammam from September 2011 to September 2013. All the patients with corneal ulcers were identified and were selected for the study with the following inclusion and exclusion criteria

Inclusion criteria: 1.Patients with corneal ulcers above 2 years of age. 2.All stages of corneal ulcer.

Exclusion criteria: 1.Infants with corneal ulcers 2. Peripheral corneal ulcers with autoimmune etiology 3.Moorens ulcer

Results: This study gives

1.The nature of trauma in relation to etiology of corneal ulcers, and its statistical significance.

2.The level of visual improvement with varied locations of ulcer over cornea and its statistical significance.

3.The level of visual improvement with varied etiology of corneal ulcer and its statistical significance.

4.To analyse possible method of reducing the incidence of corneal ulcers.

Conclusions: In the study of 200 cases, it is observed that better results are obtained if the following measures are taken in the management of corneal ulcers: Health Education, Early Diagnosis, Immediate Treatment
\end{abstract}

\section{INTRODUCTION}

Corneal ulcer is one of the major causes of blindness in India. It is one of the important ophthalmic conditions causing significant morbidity especially in developing countries.
Corneal infections are known to be the second most significant cause of monocular blindness rated after unoperated cataract in some developing nations in particular and in the tropics in general (1). Corneal ulcer is the second commonest cause 
of preventable blindness next to cataract among people in Asia, Africa\& in the Middle East ${ }^{(2)}$. The incidence of corneal ulcer is more among rural population because most of them depend on agriculture for their livelihood and thus their eyes are exposed to dust, dirt and foreign body. Industrial injuries, application of irritants and interference by quacks are some other important cases of corneal ulcer. Corneal ulcers are caused by different microbiological agents. Microbiological causes of suppurative corneal ulcers vary considerably in different geographical areas ${ }^{(3)}$. Bacteria and fungi are frequently responsible for suppurative corneal ulcers especially in the developing countries (4). Indiscriminate use of antibiotics and steroids is responsible for the increasing incidence of fungal ulcers of cornea. Injudicious topical application of cortisone and its derivatives combined with antibiotics may not only favour the growth of fungi but may cause invasive infection ${ }^{(5)}$. Among the important predisposing factors related to corneal ulcer are trauma, chronic ocular surface disease, contact lens usage, ocular surgery, corneal anaesthetic abuse, Diabetes mellitus, Vitamin deficiency, immunodeficiencies ${ }^{(6)}$

\section{AIMS AND OBJECTIVES}

Aim: This study attempts in finding the etiology of corneal ulcers and its profile of clinical presentation and response to treatment in patients attending Ophthalmology OP at Mamata General Hospital, Khammam.

\section{Objectives}

$>$ To determine the age and sex incidence of corneal ulcers

$>$ To determine the living conditions, occupation, economic status in relation to corneal ulcers

$>$ To identify the predisposing cause for corneal ulcers

$>$ To identify the nature of trauma in relation to corneal ulcers
$>$ To find out the incidence of different causative agents of corneal ulcers

$>$ To analyse possible method of reducing the incidence of corneal ulcers

\section{MATERIAL AND METHODS}

The present study of aetiology and treatment of corneal ulcer was undertaken on the patients attending to Ophthalmic department of Mamata General Hospital, Khammam from September 2011 to September 2013.

The study was made with special reference to the aetiology, its predisposing factors, microbiology and the response to treatment. Detailed history regarding age, sex, economic status and occupation with particular reference to protection of the eyes. The mode of onset of eye condition and factors like injury, foreign body damaging the cornea were ascertained from the patients.

On ocular examination any condition predisposing to corneal ulcer, lacrimal passages and their patency, digital tonometry and vision were recorded. Regarding ulcers - its shape, size, depth etc., were recorded and anterior chamber, iris, and pupil, its reactions were recorded. General examination was done with special reference to malnutrition, avitaminosis etc.

Inclusion criteria: 1. Patients with corneal ulcers above 2years of age , 2. All stages of corneal ulcer

Exclusion criteria: 1 . Infants with corneal ulcers 2. Peripheral corneal ulcers with autoimmune etiology 3. Moorens ulcer

Corneal ulcer scrapings were taken and studied under microscope with methylene blue, gram stain, and potassium hydroxide $10 \%$. Prior to antibiotic application, corneal ulcer scrapings were inoculated in Hartey's broth for culture of bacteria and inoculated on Sabouraud's medium for culture of fungi. Special Investigations like urine for albumin and sugar, estimation of serum protein and total W.B.C. count. Follow up was done after appropriate treatment and nature of complication and treatment were studied. 


\section{OBSERVATIONS}

In this study of 200 cases of corneal ulcers, a detailed recording of case history, examination, treatment and follow up is done and the following observations are made from the patients who attended the Department of Ophthalmology, Mamata General Hospital, Khammam. During the two year period from September 2011 to September 2013,about 21,922 new patients attended the Ophthalmic out patient department and out of them 219 cases were corneal ulcers. The percentage of corneal ulcers is $1 \%$.

\section{AGE INCIDENCE}

The age group between 21 and 60 is more prone for corneal ulcers and this accounted for $73 \%$ of cases. This is because most of the working group falls in this category. The incidence is less in children because tissue resistance and defense mechanisms are good.

\section{SEX INCIDENCE}

It is more common in males than females, which is explained by the fact that they are exposed to greater risk of injury to the eye. But, a good number of females also suffer from corneal ulcer because they come from poorer classes and they have to work outside in the fields to earn their livelihood.

\section{LIVING CONDITIONS}

The rural population has a higher incidence of corneal ulcers because of their frequent exposure to dust, dirt and foreign bodies. This is also due to lack of proper education regarding eye diseases and also due to false beliefs and customs in treating the eye problems like application of natural irritants, rubbing with gold ring in eye etc.

\section{OCCUPATION}

The farmers and daily labourers are more prone to injury to the eye or fall of foreign body in the eye. Hence, occupation is an important factor in the causation of corneal ulcer.

\section{PREDISPOSING CAUSE}

Injury or foreign body account for most of the cases of the present series

Table 1: Percentage Of Cases With Different Modes Of Trauma

\begin{tabular}{|l|l|l|}
\hline Nature of Trauma & No. of cases & Percentage \\
\hline Injury with vegetative matter & 62 & $38.2 \%$ \\
\hline Injury with wooden object (stick) & 40 & $24.69 \%$ \\
\hline Injury with stone & 14 & $8.64 \%$ \\
\hline Injury with animal tail & 2 & $1.24 \%$ \\
\hline Fall of foreign body & 34 & $20.98 \%$ \\
\hline Fall of insect & 10 & $6.17 \%$ \\
\hline
\end{tabular}

Table-1 shows of percentage of cases with different modes of trauma where injury with vegetative matter accounting for maximum number of cases(38.2\%). Only 4 cases showed chronic dacryocystitis and $17 \%$ of cases did not give anyrelevant cause. Although percentage of cases is more with vegetative matter, the same is the cause for fungal corneal ulcers when compared with non vegetative matter according to SPSS analysis. 
Table 2: Nature of trauma in relation to etiology of corneal ulcers, and its statistical significance

\begin{tabular}{|l|l|l|l|l|l|}
\hline & & BACTERIAL & FUNGAL & VIRAL & TOTAL \\
\hline ETIOLOGY & $\begin{array}{l}\text { INJURY WITH VEG. } \\
\text { MATTER }\end{array}$ & 13 & 92 & 2 & 107 \\
\hline & INJURY WITH STONE & 36 & 18 & 2 & 56 \\
\hline & NIL & 16 & 3 & 18 & 37 \\
\hline & TOTAL & 65 & 113 & 22 & 200 \\
\hline
\end{tabular}

Value df

Pearson Chi Square $128.629 \quad 4$

$P$ value $\quad 0.00001$

$\mathrm{P}$ value $<0.05$ Significant

Association of injury with veg. matter with fungal infection is shown to be statistically significant.

Table-2 gives the nature of trauma in relation to etiology of corneal ulcers, and there was a statistical significance ( $\mathrm{p}-0.00001$, Pearson chi square value-128.63, degree of freedom-4). Also with the given treatment, out of 113 fungal corneal ulcers 71 cases showed improvement of visual acuity in the range of 6/24 -6/60 . Among 200 cases, 122 corneal ulcers with different etiology were improved to visual acuity of 6/24$6 / 60$ and the pvalue for this association was 0.007 (Pearsons chi square value- 14.25, degree of freedom-4)which is statistically significant. This shows that more number of cases were benefited with prescribed treatment without affecting their regular earning where most of them are from a low socioeconomic status.

Table 3: Level of visual improvement with varied etiology of corneal ulcer and its statistical significance

\begin{tabular}{|l|l|l|l|l|l|}
\hline & & Bacterial & Fungal & Viral & Total \\
\hline & $6 / 6-6 / 18$ & 21 & 22 & 7 & 50 \\
\hline Visual Acuity & $6 / 24-6 / 60$ & 42 & 71 & 9 & 122 \\
\hline & $<6 / 60$ & 2 & 20 & 6 & 28 \\
\hline & Total & 65 & 113 & 22 & 200 \\
\hline
\end{tabular}

Value df

Pearson Chi Square $\quad 14.250 \quad 4$

P Value $\quad 0.00$

Table-3 shows level of visual improvement with varied etiology of corneal ulcer and its statistical significance.

Table 4: Level of visual improvement with varied locations of ulcer over cornea and its statistical significance

\begin{tabular}{|c|c|c|c|c|c|}
\hline & & $6 / 6-6 / 18$ & $6 / 24-6 / 60$ & $<6 / 60$ & Total \\
\hline & Central & 30 & 74 & 23 & 127 \\
\hline $\begin{array}{l}\text { Location of } \\
\text { ulcer }\end{array}$ & $\begin{array}{l}\text { Mid- } \\
\text { Periphery }\end{array}$ & 14 & 46 & 5 & 65 \\
\hline & Periphery & 5 & 1 & 2 & 8 \\
\hline & Total & 49 & 121 & 30 & 200 \\
\hline
\end{tabular}

Pearson Chi Square $\quad 12.938 \quad 4$

P Value 0.012

According to the table-4, 121 cases had shown a moderate improvement in visual acuity of 6/24$6 / 60$ irrespective of location of corneal ulcer. Also

74 cases of 127 central corneal ulcers showed a moderate visual improvement of 6/24-6/60 giving a statistically significant $\mathrm{p}$ value of 0.012 
(Pearsons chi square value-12.94, degree of freedom-4).

\section{TYPES OF ORGANISMS ISOLATED IN CULTURE}

Fungal isolates were detected in 56\% cases, bacterial isolates in $28 \%$ cases, viral isolates in $9 \%$ cases, and in $7 \%$ cases no organism is isolated. Bacterial pathogens isolated from 56 culture positive bacterial keratitis cases: The incidence of gram positive cocci was 58\% Predominance of Staphylococcus aureus of $16 \%$ was noticed. Pseudomonas was the most common gram negative bacteria with $10.7 \%$. Fungal pathogens isolated from 112 culture positive fungal keratitis patients: Among fungi, Aspergillus, Fusarium, Curvularia, Candida, Pencilliumare isolated from cultures of corneal scrapings on Sabourauds medium. Aspergillus and Fusarium species were found to be the most common fungal pathogens. Aspergillus species $(33.9 \%$ of the total fungal etiology)in the present study .Fusarium incidence of $17.8 \%$ was observed.

\section{METHODS OF TREATMENT}

In all the cases recorded, the treatment is started with topical instillation of fortified gentamycin eye drops every 15 minutes initially and once in an hour later, along with Ciprofloxacin eye ointment twice daily. The antibiotics are changed if necessary after receiving the culture report in each case. It is observed that frequent instillation of fortified antibiotic drops in the eye gives better results in many corneal ulcers.

\section{MEASURES FOR BETTER RESULTS}

In the study of 200 cases, it is observed that better results are obtained if the following measures are taken in the management of corneal ulcers.

Health Education: It plays an important role in prevention of corneal blindness. It should be improved so that the patient should be brought to the Ophthalmologist soon after injury to the eye. Farm workers and industrial workers, health personnel are educated regarding eye hygiene, preventive measures.

Early Diagnosis: Early diagnosis of corneal ulcer plays a major role in the treatment so that serious sight threatening complications could be avoided. Early isolation of the organism and the use of appropriate antibiotic will help in better healing of the ulcer.

Immediate Treatment: Use of proper antibiotic as early as possible after investigations will be much helpful in controlling the corneal ulcers. If the ulcers are not responding to antibiotics antifungal treatment should be started along with antibiotics till the culture report is received and stop antibiotics if the culture report for fungal growth is positive.

Treatment of Complications. In corneal ulcers with impending perforation, cyanoacrylate tissue adhesives are used. In ulcers that have already perforated, cynoacrylate tissue adhesives, placental membrane grafting can be done. In ulcers that have been with the formation of nebula and leucoma, Lamellar keratoplasty or Penetrating Keratoplasty can be done.

\section{DISCUSSION}

In the present study, corneal ulceration was seen in age group between 21-60 accounting for $73 \%$,higher in males(61\%)than in females $(39 \%)$ as observed in Kashmir(65\%),South India(65\% and $56.7 \%$ ) and Ghana (69.3\%).

Corneal ulcers is more common in rural population $(68 \%)$ in the present study as observed in other studies of Basaket al(62\%) \&Bhartiet al $(65 \%)$.

Trauma was the most common predisposing factor (59\%) matching other studies from Gangetic West Bengal(64\%), South India and Madhurai, India $(65.4 \%)$ but differing in Ghana (39\%). Corneal injury with vegetative matter $(38.2 \%)$ is more common in the present study as found in the study by Basak et al. Economically low status people $(75 \%)$ are more effected as observed in other studies in South India (68\%) and Ghana (65\%). There was higher incidence of keratitis among 


\section{JMSCR Vol||4||Issue||02||Page 9199-9206||February}

farmers $(41.5 \%)$ followed by daily labourers (38.5\%) and carpenters (10\%) in this study which coincides well with other studies. Injury with vegetable matter and wooden objects representing farmers coincides well with other studies $(1,9,10,13)$.

Table 5: Comparision With Other Studies Across India And World

\begin{tabular}{|c|c|c|c|c|c|}
\hline & $\begin{array}{l}\text { Present } \\
\text { study }\end{array}$ & $\begin{array}{l}\text { Basaket } \\
\text { al }\end{array}$ & $\begin{array}{l}\text { Bharti } \\
\text { et al }\end{array}$ & Hagan et al & Lecket al \\
\hline $\begin{array}{l}\text { Culture } \\
\text { Positivity }\end{array}$ & $93 \%$ & $67.7 \%$ & $69.5 \%$ & $57.3 \%$ & \\
\hline $\begin{array}{l}\text { Bacterial } \\
\text { Keratitis }\end{array}$ & 28 & 24.8 & 63.2 & 25 & 29.3 \\
\hline Gram positive & 58 & 71 & 65 & - & - \\
\hline Gram negative & 42 & 28.2 & 25.5 & - & - \\
\hline S.aureus & 28 & 42.6 & - & 4.7 & \\
\hline $\begin{array}{l}\text { Coagulase } \\
\text { negative } \\
\text { Staphylococci } \\
\end{array}$ & 17.8 & 7 & 16.77 & 17.4 & 22.2 \\
\hline Streptococcus & 6 & 9.4 & 41.8 & 37.5 & 12.6 \\
\hline Pseudomonas & 6 & 21.1 & 21.24 & - & 52.5 \\
\hline Fungal keratitis & 56 & 62.7 & 32 & $\begin{array}{l}35 \% \text { from South } \\
\text { Florida, 36\% from } \\
\text { Bangladesh,17.6\% } \\
\text { Nepal,46.8\% Ghana }\end{array}$ & $\begin{array}{l}37.6 \% \text { in Ghana, } 44 \% \text { in } \\
\text { South India }\end{array}$ \\
\hline Aspergillus & 33.9 & 59.8 & 24.3 & 15.3 & $\begin{array}{l}\text { High(Fusarium\&Aspergillus } \\
61 \% \text { of all fungal infection } \& \\
83 \% \text { of all fungal isolates }\end{array}$ \\
\hline Fusarium & 17.8 & 21.2 & 45.8 & 52.3 & High \\
\hline Candida & 10.7 & 1.1 & NIL & $\begin{array}{l}0.7 \% \text { of all culture } \\
+ \text { ve \& } 1.5 \% \text { of fungal } \\
\text { etiology }\end{array}$ & - \\
\hline
\end{tabular}

The observations of this study are compared in table-5 to those in various studies. Total microbial etiology of $93 \%$ compares well $(1,7,9,10,11)$. Bacterial keratitis of $28 \%$ compares well with other studies $(1,7,9,10,11,15)$ but was rather high in Nepal (7) though relatively low in Ghana (12). Fungal isolates were detected in $56 \%$ cases, Bacterial isolates in $28 \%$ cases, viral isolates in $9 \%$ cases, and in $7 \%$ cases no organism is isolated. Similar figures were also noted by other authors from India. The frequency of distribution of fungal species detected in present study is equally comparable with that of others. When compared to the number of fungal isolates, less bacterial pathogens were detected in the present study. Regarding distribution of bacteria causing suppurative corneal ulcers, similar pattern was reported by other investigators (14). Among fungi, Aspergillus, Fusarium, Curvularia, Candida, Pencilliumare isolated from cultures of corneal scrapings on Sabourauds medium. Aspergillus and Fusarium species were found to be the most common fungal pathogens in other studies $(17,18,19)$. Aspergillus species $(33.9 \%$ of the total fungal etiology) in the present study matches other studies $(7,8,10)$. Fusarium incidence of $17.8 \%$ was similar in Eastern India (3). However, it was predominant in South India and Ghana $(7,8,9,11,12)$. The incidence of gram positive cocci $(58 \%$ of bacterial etiology) coincides with 
other studies $(1,7,9,15)$. Predominance of Staphylococcus aureus coincides well with other studies. Pseudomonas was the most common gram negative bacteria in line with several studies $(1,7,9,15)$.

From antimicrobial sensitivity pattern, it appears that approximately $50 \%$ patients with bacterial etiology would have responded to Ciprofloxacin mono therapy. Instead, if fortified therapy was employed, a majority of patients would respond. Levofloxacin, Tobramycin, Gentamycin were better effective drugs against most of the gram positive and gram negative bacteria. Chloramphenicol, the frequently used ophthalmic antibiotic was found to be less effective against most of bacterial isolates except Streptococcus pneumonia \& Staphylococcus epidermidis. This poor performance of Chloramphenicol may be due to its inappropriate and enthusiastic use seen in common practice leading to drug resistance. Similar pattern of antibacterial susceptibility among corneal ulcer patients was reported by other authors(16).

A major red flag for fungal infection is agricultural trauma with vegetable matter. According to table 2 and 3 , out of 113 fungal corneal ulcers, etiology of 92 being injury with vegetative matter, 71 fungal ulcer cases showed visual acuity improvement in the range of $6 / 24$ to $6 / 60$. This shows that more number of cases were benefited with prescribed treatment without affecting their regular earning where most of them are from a low socioeconomic status. The only medication commercially available for fungal keratitis is Natamycin, which is usually applied hourly during the day. Natamycin's best activity is against Fusarium mold. It has less efficacy against Candida yeast. Fungal keratitis requires medication for six weeks on average. A particularly worrisome risk in infection with fungi, is deep penetration, not only into the cornea but also into the eye itself. If the infection doesn't resolve, medical options are limited as the topical medications do not penetrate deeply and Corneal transplantation should be considered in such cases.

Most adjunctive medical and surgical interventions for corneal ulcers focus on providing surface support - with lubrication, collagenase inhibitors, and growth factors - and shielding the cornea. Approaches include bandage contact lenses, punctal occlusion, autologous serum eyedrops, amniotic membrane, and tarsorrhaphy, among others. In cases of stromal melting, topical collagenase inhibitors such as $\mathrm{N}$-acetylcysteine, doxycycline, or medroxyprogesterone as well as oral vitamin C $1,000 \mathrm{mg}$ per day may be prescribed. Cyanoacrylate glue, a Gunderson (conjunctival) flap, or penetrating keratoplasty may be indicated.

\section{REFERENCES}

1. Basak SK,BasakS,MohantaA,Bhomwick A. Epidemiological and microbiological diagnosis of suppurative keratitis in gangetic West Bengal,EasternIndia.Indian J Opthalmol 2005;53:17-22

2. Thylefor B. Epidemiological Patterns Ocular Trauma. Aust N A J Ophthalmol 1992; 20: 95-98.

3. Leek AK, Thomas PA, Hagan M, Kaliamurthy, Ackuaku E, John M, et al. Aetiology of Suppurative Corneal Ulcers in Ghana and South India, and Epidemiology of Fungal Keratitis. $\mathrm{Br} \mathbf{J}$ Ophthalmol 2002; 86: 1211-1215.

4. P rosantGrag MS. Corneal Ulcer Diagnosis and Management. Community Eye Health 1997; 12:30.

5. Ross H W, Laibson PR. Keratomycosis. Am J Ophthalmol 1972; 74: 438441.

6. Ta nure MA, Cohen EJ, Sudesh S, et al. Spectrum of Fungal keratitis at Wills Eye Hospital Philadelphia, Pennsylvania. Cornea 2000; 19: 307-312.

7. Thomas PA. Mycotic keratitis - an underestimated mycosis. J Med Vet Mycol. 1994; 32: 235-256. 
8. Bharathi MJ, Ramakrishnan R, Vasu S, Meenakshi R, Palaniappan R. Epidemiological characteristics and laboratory diagnosis of fungal keratitis: A three-year study. Indian J Ophthalmol 2003;51:315-21.

9. Srinivasan $\mathrm{M}$, Gonzales CA, George C, Cevallus V, MascarehasJM,AsokanB, et al. Epidemiology and aetiological diagnosis of corneal ulceration in Madurai, south India.Br J Ophthalmol 1997;81:965-71.

10. Bashir G, Shah A, Thokar MA, Rashid S, Shakeel S. Bacterial and fungal profile of corneal ulcers.A prospective study. Indian J PatholMicrobiol 2005;48:273-7.

11. Hagan M, Wright E, Newman M, Dolin P, Johnson GJ.Causes of suppurative keratitis in Ghana. Br J Ophthalmol 1995;79:10248.

12. Leck AK, Thomas PA, Hagan M, Kaliamurthy, Ackuau E, John M, et al. Aetiology of suppurative corneal ulcers in Ghana and south India, and epidemiology of fungal keratitis. $\mathrm{Br} \mathrm{J}$ Ophthalmol 2002;86:1211-5.

13. Verenker MP, Borkar S, Pinto MJ, Pradeep N. Study of mycotic keratitis in Goa.Indian J Med Microbiol 1998;16:5860.

14. Rahman AK. A Study on External Ocular Infections (Bacterial and Fungal) with Emphasis on Corneal Ulcer ( Unpublished M. Phil. Thesis), Department of Microbiology, IPGMR, Dhaka, Bangladesh, 1995.

15. Bharathi MJ, Ramakrishnan R, Vasu S, Meenakshi R, Shivkumar C, Palaniappan R. Epidemiology of bacterial keratitis in a referral centre in south India. Indian J Med Microbiol 2003;21:239-45.

16. Steinert RF. Current Therapy for Bacterial Keratitis and Bacterial Conjunctivitis. Am J Ophthalmol 1991;112 (Suppl): 10- 14.
17. Kunimoto DY, Sharma S, Gary P, Gopinathan U, Miller D, Rao G. Corneal ulceration in the elderly in Hyderabad, South India. Br J Ophthalmol.2000; 84:5459.

18. Mirshahi A, Ojaghi H, Aghashahi D, Jabarvand M. Fungal keratitis in patients at Farabi Hospital, Tehran (1998- 1999) [in Persian]. Bina. 1999; 5(2): 135-143.

19. Berenji F, Elahi SR, Fata AM, Khakshour H, Darakhshan A. Fungal keratitis in patients at Imam Reza Hospital, Mashhad (1982-2001) [ in Persian]. Med J Mashhad Univ Med Sci. 2003; 45:49-54.

Synopsis: This study gives the nature of trauma in relation to etiology of cornalulcers. The level of visual improvement with varied locations of ulcer over cornea and with varied etiology of corneal ulcer also analyses possible method of reducing the incidence of corneal ulcers. 